\title{
Gross Morphology of Scapula in Indian Wild Cat (Felis silvestris ornate: Gray, 1830)
}

\author{
Dharani Palanisamy, M.P.S. Tomar*, Prasanth Babu Ankem, Raj Sekhar Ullakula, \\ Naveen Jonnalagadda and Venkatesh Korampalli
}

\author{
Department of Veterinary Anatomy, College of Veterinary Science, Proddatur (Sri \\ Venkateswara Veterinary University), Kadapa (A.P.) - 516360, India
}

*Corresponding author

\section{A B S T R A C T}

\section{Keywords \\ Hamate and Suprahamate process, Scapula, \\ Subscapular fossa, Supra \\ and infraspinous fossae Wild cat \\ Article Info \\ Accepted: \\ 20 March 2018 \\ Available Online: \\ 10 April 2018}

The gross morphological study on the scapula of Indian Wild cat revealed that it was flat and quadrangular bone with two surfaces, four borders and four angles. The scapular spine was well developed with increasing height distally and its termination in the acromian process. The acromian process was divided in to hamate and suprahamate process which were triangular and in the form of quadrilateral plate, respectively. The ratio of supra and infraspinous fossae was approximately 1:1. The subscapular fossa presented four ridges and the nutrient foramen was present near the scapular neck. The scapular notch was formed by the continuation of ventral border and it was extended up to supra-glenoid tubercle. The coracoid process was well developed and hook like. The glenoid cavity was shallow and oval with laterally placed glenoid notch.

\section{Introduction}

Felidae is the family name of the cats and members of this family are commonly called felids or felines. Felids are strictly carnivores and classified under the order Carnivora of Class Mammalia. The most familiar felid is the domestic cat, which first became associated with humans about 10,000 years ago, but the family includes many other wild cats too including the big cats (Nowak, 1999).

The wild cats are classified under the genus Felis and species silvestris. The latest phylogeographical analysis suggested that the wildcat (Felis silvestris) consisted of five subspecies groups under same generic and specific taxa viz. the African wildcat $(F$. silvestris lybica), the Asian wildcat ( $F$. silvestris ornata), the European wildcat ( $F$. silvestris silvestris), the southern African wildcat ( $F$. silvestris cafra) and the Chinese alpine steppe cat $(F$. silvestris bieti) as per the reports of Driscoll et al., 2007 and Macdonald et al., 2010.

The wild cat is the most common and widely distributed wild felid and thus listed under the species of least concern in IUCN (International Union for Conservation of 
Nature and Natural Resources) red list (IUCN, 2013). The geographical distribution of wild cats includes most of the Africa, Europe and Southwest and central Asia including India, China and Mongolia.

Although, the species is widely distributed but the available literature shows very meagre information on the anatomy of wild cats thus the present investigation was planned on the scapula bone of wild cat to record its osteological features.

\section{Materials and Methods}

The present study was conducted on the 4 scapulae of adult Wild cat in the Department of Veterinary Anatomy, College of Veterinary Science, Proddatur.

The bones were collected after maceration and observed for gross morphological features. The terminologies were adopted from Boyd et al., 2001; Nomina Anatomica Veterinaria (2017) and Tomar et al., (2018).

\section{Results and Discussion}

In present study, the scapula of wild cat was a flat, roughly quadrangular bone, which was located on the lateral aspect of the thorax. The quadrangular shape of scapula was also mentioned in late Miocene amphicyonid (Magericyon anceps) by Siliceo et al., (2014), in civet cat by Sarma et al., (2017) and in Indian tiger by Tomar et al., (2018) however, Sundaram et al., (2015) mentioned a triangular scapula in orange rumped agouti (Dasyprocta leporina).

It was directed downward and forward. The present observations tallied the earlier reports of Konig and Liebich (2009) in mammals, Sreeranjini et al., (2008) in leopard, Tomar et al., (2012) in tiger and leopard, Sarma et al., (2017) in Civet cat, Mahapatra et al., (2016) and Tomar et al., (2018) in Indian Tiger and Rosu et al.,(2016) in cheetah. However, Nzalak et al., (2010) mentioned about triangular scapula in lion. The lateral surface was divided into two almost equal fossae by well-developed scapular spine; namely, cranially located supra-spinous fossa and caudally located infra-spinous fossa (Fig. 1). The spine was gradually increased in height towards distal end (Fig. 4). The spine inclined backward and over hanged infra-spinous fossa and it had two surfaces viz. anterior and posterior surfaces of scapular spine. The tuber spinae scapulae was in the form of elongated ridge which was rough for muscular attachment (Fig. 1). The scapular spine terminated in acromion process as also reported by Konig and Liebich (2009); Sreeranjini et al., (2008); Tomar et al., (2012; 2018); Mahapatra et al., (2016); Sarma et al., (2017); Rosu et al., (2016).

The acromion process was composed of hamate and supra-hamate process (Processus hamatus et suprahamatus) (Fig. 1 and 3) similar to the findings of Konig and Liebich (2009); Sreeranjini et al., (2008); Tomar et al., (2012; 2018); Mahapatra et al., (2016); Sarma et al., (2017); Rosu et al., (2016) However, Sarma et al., 2017 named them as acromion and metacromian process. Hamate process was triangular with blunt end which over hanged the glenoid notch.

The supra-hamate process was quadrangular and directed caudally. The supra-spinous fossa had undulating surface and the infra-spinous fossa was triangular and had flattened surface in wild cat (Fig. 1), similar to the observations in scapula of other carnivores (Konig and Liebich, 2009; Sreeranjini et al., 2008; Tomar et al., 2012 and 2018; Sarma et al., 2017; and Rosu et al., 2016). The nutrient foramen was noticed in supra and infra-spinous fossae whereas it was observed in only infra-spinous fossa by Sreeranjini et al., (2008) in Leopard. 


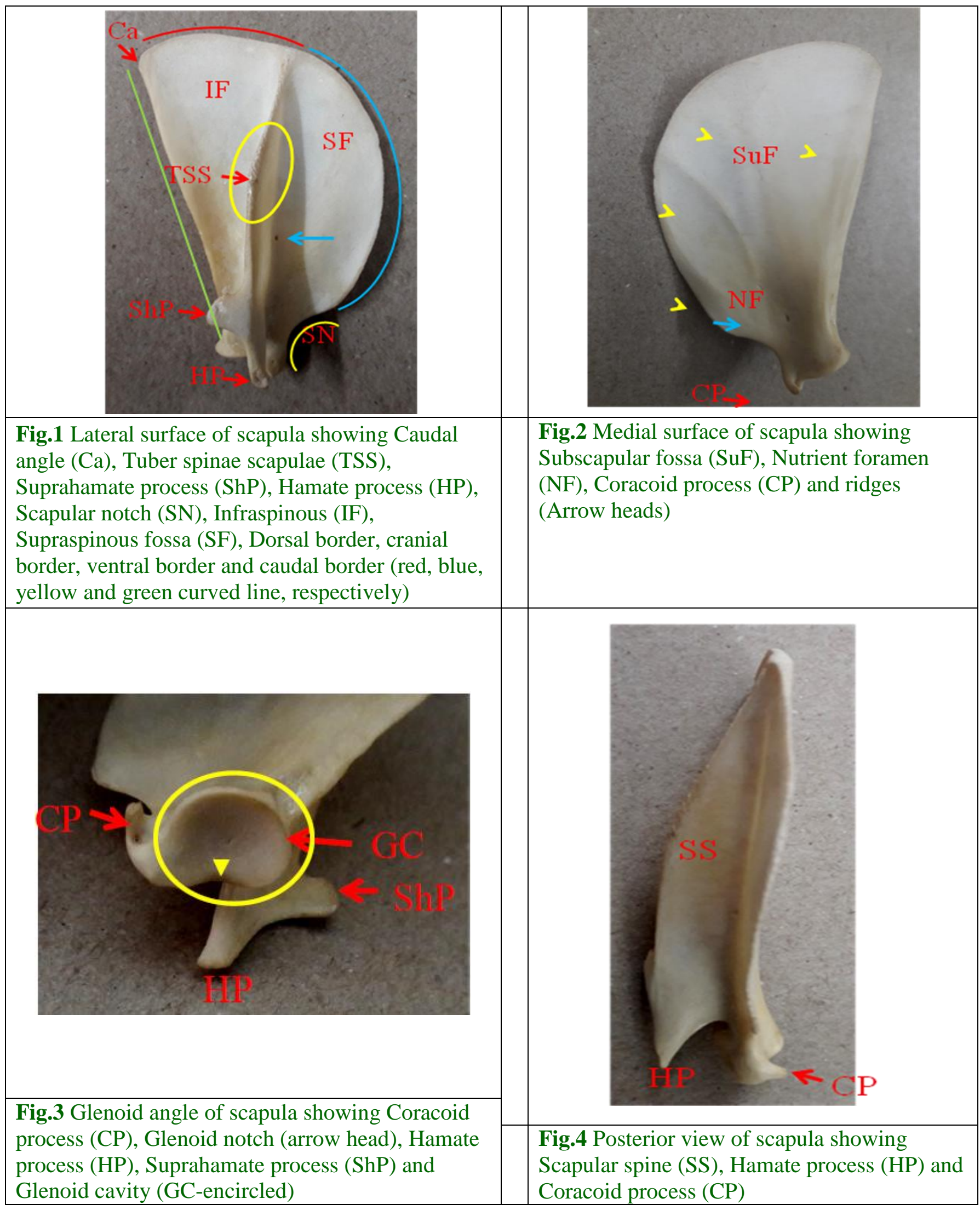


The medial surface presented subscapular fossa (Fossa subscapularis) with four ridges viz. $1^{\text {st }}$ (Cranial one) was anteriorly curved, $2^{\text {nd }}$ was posteriorly curved whereas $3^{\text {rd }}$ and $4^{\text {th }}$ were straight (Fig. 2). The presence of these ridges were also observed by Sarma et al., (2017) in civet cat and Tomar et al., 2012 and 2018 in tiger and leopard however they observed 5 ridges in leopard whereas 2 ridges in tiger.

The depth of subscapular fossa was more anteriorly as it was concave in anterior half while it became flat caudally. The nutrient foramen observed in the distal third near the neck of scapula (Column scapulae). The cranial border was thin, strongly curved and continued with ventral border. The caudal border was thick and straight. The dorsal or vertebral border was slightly convex. The ventral border was small, convex and in continuation with cranial border. The craniodorsal and cranio-ventral angles were not well marked whereas the caudal angle was thick (Fig. 1).

The ventral angle was in the form of an articular shallow and oval glenoid cavity (Fig. 3 ), which was in accordance with the earlier reports in various carnivores (Konig and Liebich, 2009; Sreeranjini et al., 2008; Nzalak et al., 2010; Tomar et al., 2012; 2018; Sarma et al., 2017; Rosu et al., 2016). The glenoid notch was observed on the lateral aspect of the rim however, Sarma et al., (2017) observed indistinct glenoid notch in civet cat. The scapular notch was formed by the continuation of ventral border and it was extended up to supra glenoid tubercle (Fig. 1), similar to the finding of Sreeranjini et al., (2008) in leopard and Tomar et al., (2018) in tiger. It presented a coracoid process, which was hook-like directed medially backward and downward (Fig. 3), similar to the observation of Tomar et al., (2018) in Indian tiger.

\section{References}

Boyd, J.S., C. Paterson and May, A.H. 2001. Colour Atlas of Clinical Anatomy of Dog and Cat. 2nd edn. Publ., Mosby Wolfe, Glasgow, UK. 62-87.

Driscoll, C.A., Marilyn Menotti-Raymond, Alfred L. Roca, Karsten Hupe, Warren E. Johnson, Eli Geffen, Eric H. Harley, Miguel Delibes, Dominique Pontier, Andrew C. Kitchener, Nobuyuki Yamaguchi, Stephen J. O'Brien, and David W. Macdonald. 2007. The Near Eastern Origin of Cat Domestication. Science. 27 (317): 519-523.

IUCN Red List, 2013, "Felis Silvestris (Wildcat, Wild Cat)" The IUCN Red List of Threatened Species. URL: http://www.iucnredlist.org/details/8543/ 0 .

Konig, H.E and Liebich, H.G, 2009. Veterinary Anatomy of Domestic Mammals, Textbook and colour Atlas, $4^{\text {th }}$ Edn, Schattauer $\mathrm{GmbH}$, Holderlinstrable, Stuttgart, Germany, pp. 145-149.

Macdonald, D.W., N. Yamaguchi, A.C. Kitchener, M. Daniels, K. Kilshaw and Driscoll C, 2010, "Reversing Cryptic Extinction: The History, Present, and Future of the Scottish Wildcat" In Biology and Conservation of Wild Felids Eds D. W. Macdonald A. J. Loveridge (Oxford University Press, Oxford).

Mahapatra, A., Sathish K. Pathak, Amarpal and Pawde, A.M. 2016. Morphological and Certain Morphometrical Study of Scapula of Indian Tiger. Indian Journal of Veterinary Anatomy, 28(2): 77-79.

Nomina Anatomica Veterinaria, 2017, 6th Edn, Prepared by International Committee on Veterinary Gross Anatomical Nomenclature \& authorized by General assembly of World 
Association of Veterinary Anatomy, Knoxville, TN (USA)-2003.

Nowak, R. M., 1999. Walkers Mammals of the World. Baltimore John Hopkins university press.74-92.

Nzalak, J.O., M. M. Eki, M.H. Sulaiman, A. D. Umosen, S.O. Salami, S.M. Maidawa and Ibe, C.S. 2010. Gross Anatomical Studies of the Bones of the Thoracic Limbs of the Lion (Panthera leo). Journal of Veterinary Anatomy, 3(2): 65-71.

Rosu, P.M., G. Predoi, C. Belu, B. Georgescu, I. Dumitrescu and Raita, S.M. 2016. Morphometric biodiversity in cheetah thoracic limb bones: a case study. Scientific Works. Series C. Veterinary medicine, Lxii (1): 41-45.

Sarma, K., J. S. Sasan and Shalini Suri. 2017. Gross and Morphometrical Studies on Scapula of Civet Cat (Viverricula indica). International Journal of Pure and Applied Bioscience, 5 (6): 80-85.

Siliceo, G., M. J. Salesa, M. Anton, J. F. Pastor and J. Morales. Comparative Anatomy of the Shoulder Region in the late Miocene Amphicyonid (Magericyon anceps) carnivora: Functional and Paleoecological
Inferences. Journal of Mammalian Evolution, (DOI: 10.1007/s10914-0149270-9).

Sreeranjini, A.R., Indu V. Raj, N. Ashok and Harshan, K.R.2008. Gross Anatomical Studies of the Scapula in Leopard (Panthera pardus). Journal of Veterinary and Animal Sciences. 39: 47-48.

Sundaram, V., N. Dumas, A. Adogwa, S. Rao and S. B. Nayak. 2015. Morphological Studies of the Forelimb Skeleton of the Orange Humped Agouti (Desyprocta leporine Linnaeus 1758). Annual Research and Review in Biology, 8(4): 1-9.

Tomar, M.P.S., A.B. Shrivastav and RakhiVaish. 2012. Comparative morphology of scapula in tiger (Panthera tigris) and leopard (Panthera pardus). Indian Wildlife Year Book. 10: 71-73.

Tomar, M.P.S., J.S. Taluja, Rakhi Vaish, A.B. Shrivastav, Apra Shahi and Deepak Sumbria. 2018. Gross anatomy of scapula in Tiger (Panthera tigris). Indian Journal of Animal Research (DOI:

\section{How to cite this article:}

Dharani Palanisamy, M.P.S. Tomar, Prasanth Babu Ankem, Raj Sekhar Ullakula, Naveen Jonnalagadda and Venkatesh Korampalli. 2018. Gross Morphology of Scapula in Indian Wild Cat (Felis silvestris ornate: Gray, 1830). Int.J.Curr.Microbiol.App.Sci. 7(04): 2473-2477. doi: https://doi.org/10.20546/ijcmas.2018.704.283 